\section{Fatal impact in paradise}

- Some years ago I heard Marshall McLuhan use the phrase "global village". Global village is now a reality, for as I write, the Los Angeles earthquake, the European floods, along with the traumas of Bosnia and Somalia, are in the media daily. We have become familiar with terms such as GATT, north-south, third world, and developing world as trade moves to a global market.

One of the key issues which has concerned tobacco control advocates for some years is awareness that tobacco companies need to penetrate new markets in order to maintain or expand their current levels of production. The tobacco industry is well aware of this and industry authorities have indicated four major trends: a shift in demand for cheaper leaf from developed to developing countries, a shift to cheaper leaf, an oversupply of highprice leaf, and automation of production. ${ }^{1}$

Such issues are a challenge to tobacco control advocates. It is necessary to shift the balance of misinformation and power in favour of those countries and societies which are often marginalised or impoverished or which lack accurate sources of information and knowledge concerning tobacco. The necessary steps for progress in control of tobacco are often poorly known and little understood in some of the smaller developing countries.

Two articles in this issue of Tobacco Control refer to the difficulties faced by small countries in seeking to change smoking behaviour. The information from these two articles is pertinent to where the energies and direction for much future tobacco control efforts must lie.

The article by Woodward et $a l^{2}$ encapsulates the smoking prevalence situation in the Kingdom of Tonga.

- This report indicates that in the historic kingdom of Tonga some $62 \%$ of the men aged 20 or more years are smokers. A recent regional review has shown that many of the Asia-Pacific countries (China $61 \%$, Fiji $59 \%$, Korea $68 \%$, Macao $89 \%$, Philippines $84 \%$, Tokelau $68 \%$, and others without prevalence data such as Kiribati) have smoking rates for men in excess of $60 \%$ of the population. ${ }^{3}$ This situation existed 30 years ago in countries such as Australia, Canada, and New Zealand where now only one in four men smokes.

Following their first contacts with western culture, there is evidence that many of the Asia-Pacific countries were devastated by the introduction of infectious diseases such as dysentery, influenza, measles, smallpox, and tuberculosis, and later cholera and leprosy. Though details are often scant due to the transmission of oral history, the facts are clear. Today many of these countries face a second wave of premature death, as anthropologist Mac Marshall has described, "a second fatal impact".

The impact of non-communicable disease is now evident in many places including the oft-envisaged "paradise" in the tranquil isles of the Pacific and the playgrounds of the Caribbean. Marshall has recently highlighted the results of this second fatal impact. ${ }^{4}$ In Micronesia during 1992, cigarettes were listed as the fourth major import item $(\$ 2.5$ million dollars) ranking with motor vehicles ( $\$ 4.3$ million), rice (\$3.2 million) and alcohol (\$2.9 million)..$^{5}$ Though appearing to be more subtle, the results of this fatal impact in morbidity and mortality is probably just as devastating as the introduction in earlier centuries of communicable diseases.
In speaking of the fatal impact of tobacco in 1990 , Jimmy Carter said, "It's sobering for me to know that more Colombians died last year from smoking American cigarettes than did Americans from using Colombian cocaine." I hope that the export by the American and British transnational tobacco companies of addictive influence will receive more than scant attention in the health debate of the Clinton administration, for the smokescreen of the tobacco industry ranks above issues such as the high temperature incinerator on Johnsson Atoll or even that of French nuclear testing on Muraroa Atoll.

The news article, by Alan Blum, ${ }^{7}$ profiles the situation in the Caribbean island of Barbados and raises several important points. The first is that the situation in the Caribbean is similar to that of other island areas of the world. As Blum writes from the Caribbean about the Benson and Hedges World Series Cricket, I watch the same game in Australia and again recognise the global nature of this "fatal impact".

The second point is of more significance. If success is to be achieved, it will usually result from the dedication and tireless determination of an individual or small group of people in coalition. As Blum indicates in his article, $\mathrm{Dr}$ Tony Gale, the government health official, and the Adventist minister are a quite formidable coalition and can be catalysts for significant change. It is people such as these who give time and talent who are truly deserving of the Tobacco or Health medals offered by the World Health Organisation (WHO).

A further issue raised is the global marketing and communication network which is currently being used to bypass national boundaries and legislation by transmission of glamorous tobacco advertising. This is particularly the case in Asia with networks such as Star television. A recent visit to Manila showed multi-channel satellite television with tobacco advertising offering the "Spirit of USA" along with "Hope" and " 555 ". Such powerful imaging has to be banned for progress to be achieved globally.

These articles raise issues which global tobacco control advocates will need to address if further progress is to be achieved.

\section{A global understanding of tobacco marketing}

An understanding of the world market is essential and it will require all the resources of the WHO, the International Union Against Cancer (UICC), the American Cancer Society (ACS), and other bodies including coalitions with church agencies to turn the tide against tobacco.

In my extensive travel, a little-understood and often expressed concern by nationals is how the export of British-American addictive influence, often with little or no packaging requirements, is allowed by the exporting country. Product liability issues will increasingly be relevant to this concern. The nationals of many countries have often said, "Surely there is something they can do in the country that is exporting to stop the promotion of these products in our country." The recent development of the World Bank position on tobacco is one small step in the right direction (see Tobacco Control 1992; 1: 92). ${ }^{8}$ Much 
more needs to be done within exporting countries to ensure that importing countries are not abused through lack of information or understanding.

As economies move to more open markets, a shift in world trade is taking place. In addition, a global change is taking place in consumer awareness. The tobacco control movement needs a global focus and understanding of the world tobacco trade so as to be aware of the impact of tobacco on trade as well as death and disease in small, yet significant economies. This is especially important now that US tobacco growers are seeking to establish their own trade barriers.

\section{Development of effective control measures}

The UICC has recently produced a series of excellent brochures outlining the effective measures of tobacco control. ${ }^{\star}$ These and other measures outlining legislative controls are often little understood in developing countries and require regular education and consistent follow-up.

Progress in tobacco control will necessitate obtaining accurate prevalence of tobacco use and related disease information. Public health measures to reduce smoking have been shown to yield high benefit at low cost. ${ }^{8}$

\section{Need for development of specific health promotion organisations}

Regular increases of taxation to high levels is known to be among the most effective measures to reduce consumption of cigarettes. Few countries have been able to convince enlightened politicians and governments to hypothecate (earmark) revenues from tobacco taxes for health promotion. This should not deter our focus in encouraging small countries to pursue this strategy. Currently Iceland, Portugal, Finland, Romania, New Zealand, California, and most states of Australia have some form of hypo-

* For further information, contact: Mrs Isabel Mortara, Head, Education Department, 3 rue du Conseil-Général, 1205, Geneva, Switzerland. thecated tax on tobacco. Such initiatives are not only good tax policy, but decisions by governments that benefit public health.

\section{Development of broad coalitions of support}

Some of the most effective measures in Australia have required support from broader coalitions than merely the medical and health field. Tobacco control is an ethical issue. Churches and organisations concerned with the well-being of children are recognising that this issue cannot be neglected.

In many countries such as Tonga and Barbados, religion plays a more significant part in daily life, and the issue of tobacco control has consistently received support from religious communities.

We may have become a little desensitised to the saying "Think Globally, Act Locally", but it remains our task if we are to reduce the fatal impact in our global village.

Seventh Day Adventist Church,

HARLEY STANTON

South Pacific Division

Wahroonga, New South Wales, Australia Harley Stanton is the Chairman of the South Asia-Western Pacific UICC
Tobacco Control Project and a Regional Consultant for the Tobacco or Health Programme of the World Health Organisation.

1 Doolittle DE. Trends to 2000 (editorial) Tobacco Reporter, August 1992, p. 4.

2 Woodward A, Newland H, Kinahoi M. Smoking in the Kingdom of Tonga: report from a national survey. Tobacco Control 1994; 3: 41-5

Stanton HJ. World Health Organisation, Tobacco or Health Database, Western Pacific Regional Office, Manila, November 1993.

4 Marshall $M$. The second fatal impact: Cigarette smoking, chronic disease, and epidemiological transition in Oceania. Soc Sci Med. 1991, 33 (12): and epidem.

5 Marshall M. Consultant Report on Micronesia, Western Pacific Regional Office, Manila, Philippines: World Health Organisation, 1993.

6 Carter J. Accepting our responsibility. Second Opinion, Park Ridge Center, Chicago, Illinois, Vol 13, 1990, p 33

7 Blum A. Inspiration in the Caribbean. Tobacco Control 1994; 3: 13-4.

8 Jamison DT et al. Investing in health, world development report, 1993. World Bank, June 1993, p 89. 